\title{
Psychological Impacts of COVID-19 among College Students in Dessie Town, Amhara Region, Ethiopia; Cross-sectional Study
}

Abay W.Tadesse ( $\sim$ abaywoday@yahoo.com )

Samara University, College of Medicine and Health Sciences, Afar Region, Ethiopia.

Setegn Mihret

Wollo University

Gebeya Biset

Wollo University

Ayesheshim Muluneh

Dessie Health Science College

Research Article

Keywords: COVID-19, Psychological Impacts, Anxiety, Stress, Depression, Students, Ethiopia

Posted Date: June 30th, 2020

DOI: https://doi.org/10.21203/rs.3.rs-38100/v1

License: (c) (i) This work is licensed under a Creative Commons Attribution 4.0 International License.

Read Full License 


\section{Psychological Impacts of COVID-19 among College Students in Dessie Town, Amhara Region, Ethiopia; Cross-sectional Study}

Abay Woda Tadesse1,2, Setegn Mihret3,2, Gebeyaw Biset3,2, Ayesheshim Muluneh4,2,

\section{Affiliations:}

1Samara University, college of Medicine and health sciences, Departments of public health, Samara, Afar region, Ethiopia. 2Dream Science and Technology College Dessie, Ethiopia. 3 Wollo University, College of Medicine and Health Sciences, School of Nursing and Midwifery, Departments of paediatrics health nursing, Amhara region, Dessie, Ethiopia. 4 Dessie Health Science College Department of nursing and midwifery, Dessie Ethiopia.

Corresponding Author: Abay Woday Tadesse (MPH), E-mail: abaywoday@yahoo.com

Institutional email: abaywonday@su.edu.et

P.O.BOX: 132

\section{Co-authors email address:}

Setegn Mihret (BSc, MSc),Email: setegnmihret5@gmail.com.

Gebeyaw Biset (BSc, MSc),Email: gebeyawbiset@yahoo.com.

Ayesheshim Muluneh (BSc, MSc), Email: ashumuluneh327@gmail.com 


\section{Abstracts}

Background: The COVID-19 pandemic is a catastrophic health crisis that affects several nations across the world. Hence, such widespread outbreaks are associated with adverse mental health consequences. However, there is scarce information regarding the psychological impacts of COVID 19 on college students in Ethiopia. Thus, this study investigated the psychological impact of COVID-19 upon students.

Methods: A cross-sectional study was conducted among 422 college students who were learning at randomly selected public and private colleges and universities in Dessie town. The sample was proportionally allocated into the four randomly selected colleges and the students were recruited using a systematic random sampling technique with every 6th interval that was obtained from each college's registrar office. The data analysis was done using SPSS version 23.0. Variables with $\mathrm{p}$-value $<0.25$ in the bivariate analysis were entered into the multivariable logistic regression model. Model fitness was checked using the Hosmer-Lemeshow model fit-ness-test. Statistical significant level was declared at a p-value $<0.05$.

Results: This study involved 408 students with a response rate of $96.6 \%$. In this study, the overall psychological impact of COVID-19 among college students was 16.2\% [95\% CI: 12.7\%, 19.9\%]. Moreover, $77.2 \%$ of the students had experienced depression disorder. Similarly, $71.8 \%$ and $48.5 \%$ of students had experienced anxiety and stress disorders respectively. The multivariable logistic regression showed that being female [AOR $=1.68,95 \% \mathrm{CI} 1.09,2.91]$, having inadequate practice of prevention measures $[\mathrm{AOR}=1.74$ : 95\% CI 1.01, 3.02] and living urban residency [AOR=0.76: $95 \%$ CI $0.48,0.94]$ were the independent predictors of psychological problems among students.

Conclusions: The study revealed the level of anxiety, stress, and depression disorders are optimally high among students. Therefore, local governments should develop effective psychological interventions for students. Moreover, it is important to consider the educational enrollment types and academic years of the students during the interventions.

Keywords: COVID-19, Psychological Impacts, Anxiety, Stress, Depression, Students, Ethiopia 


\section{Introduction}

Severe acute respiratory infection (SARS) is a group of respiratory tract infections caused by a beta coronavirus (SARS-COV2) [1-3]. Corona Virus Disease-2019 (“COVID-19”) is a family of SARS caused by Novel Coronavirus and was first detected in December 2019 in Wuhan, China. Since it has been declared a global pandemic by the World Health Organization (WHO), it has made the rapid spread across the world and causes high mortality and morbidity [2-5]. Globally, there is an estimated number of 7 million cases and nearly half a million deaths [6-8]. Following this pandemic, nations across the globe have taken different preventive measures. These include movement restriction, confinement to home and closure of the school, and other social services that lead to increased psychosocial stress among the community, especially students [9-17].

A study conducted in china revealed that $53.8 \%$ of respondents had experienced moderate to severe psychological crises, in which students were found to contribute a greater number than the larger communities [18]. Another study in China revealed that around $25 \%$ of college students experienced anxiety due to the pandemic [19]. A study conducted in Singapore revealed that $14.5 \%, 8.9 \%$, and $7.7 \%$ of participants screened positive for anxiety, depression and stress respectively [20]. Pieces of evidence had suggested that the pandemic resulted in loneliness, anxiety, depression, insomnia, suicide. societal rejection, discrimination, and stigmatization among people [21, 22].

Ethiopia has taken different prevention and control measures to halt the spread of COVID-19. These include school closure, stay at home, keep social and physical distances, putting hand washing basin in places where people use in common (banks, Churches/mosques, markets), preparation of isolation centers, and establishment of state emergency at the national level [23-25]. However, still, there is no specific intervention to address the psychological impact of COVID 19 in the country.

Moreover, the studies conducted across the globe have been investigated the psychological impacts of COVID-19 pandemic predominantly focused on health care workers and patients [26-28]. Therefore, this study was intended to generate evidence regarding the prevalence of psychological problems due to COVID-19 and its determinants among college students. 


\section{Methods and Materials}

\section{Study Setting and Participants}

The community-based cross-sectional study design was conducted from April 15-May 15, 2020 to assess the psychological impacts of COVID-19 on students who were learning in the four randomly selected private and public colleges and Universities, Namely; Dream Science and Technology College, Dandi Boru College, Unity University, and Dessie Health Science College. These higher institutions are found in South Wollo Zone, Dessie city administration. Dessie city administration is located $401 \mathrm{Km}$ away from the capital city of Ethiopia, Addis Ababa. The city has eight private colleges, one private University, and three public colleges which accommodate a total of 20,907 students in different fields of study.

All active students, registered for second-semester academic year, and those 16 and above years of age were included in this study. However, students who were seriously ill during the data collection period were not included in this study.

The sample size was calculated for both determinants and prevalence of psychological problems due to COVID 19 and the maximum sample size was considered for this study. Thus, the final sample size was determined using a single population proportion formula with assumptions: 5\% type I error, 95\% Confidence Intervals, $50 \%$ proportion since no study in Ethiopia on this problem. Finally, the researchers added $10 \%$ to compensate for the non-response of participants and the final sample size became 422.

$$
\mathrm{n}=\frac{(\mathrm{Za} / \mathrm{z})^{2}(\mathrm{P})(1-\mathrm{P})}{\mathrm{d}^{2}}
$$

Where: $\mathrm{n}=$ required sample size, $\mathrm{Z} \alpha / 2=$ critical value for normal distribution at $95 \%$ confidence level (1.96), $\mathrm{p}=$ proportion of psychological problems, and $\mathrm{d}=0.05$ (5\% margin of error).

From a total of twelve colleges and universities found in Dessie city administration, four higher institutions (three colleges and one university) were randomly selected. The calculated sample size 
was proportionally allocated in each college based on the second-semester academic student number reports. To calculate the required number of participants from each college, we multiplied the total number of students actively learning in each college by the sampling fraction $(\mathrm{n} / \mathrm{N})$. The sampling fraction is approximately equal to six for all colleges. Accordingly, every 6 th participants were selected using a systematic random sampling technique from each college registrar office log-book.

\section{Study variables:}

Dependent variable: the psychological impact of COVID 19 (Yes/No) that was assessed using all of Depression, Anxiety, and Stress Scales (DASS-21).

Independent variables: sociodemographic characteristics (age, residence, sex, marital status, educational level, the field of study, income, family size, religion), knowledge, attitude and practice towards the preventive measures of COVID-19.

\section{Data Collection Tools and Procedures}

The questionnaire was adopted from studies conducted before this study [19, 29-31] and modified into context. The questionnaire was developed in the English language and it consists of sociodemographic characteristics, 20-items for knowledge, eight items for attitude, and 12-items for the practice of preventive measures against COVID-19. The psychological impact was assessed by using mental health status assessment tool, DASS-21 (i.e. the Depression, Anxiety, and Stress Scales) [29]. The tools were translated into the local language (Amharic) and back to English to keep its consistency. The tool was pretested on 5\% (21 participants) of samples other than selected colleges those found in Woldia town and some amendments were made based on the pretest findings. The data was collected using both phone-call and personal interviews. Phone-call was used for students who are out of Dessie town. The study participants were approached by trained health professionals who were working out of the selected colleges. 


\section{Data management and analysis}

The data were cleaned, coded, and entered into Epi data version 3.1 software and exported to SPSS version 23.0 for analysis. The descriptive statistics was done and the results were presented using texts, frequency tables, figures, and median with Interquartile range (IQR).

Bivariate logistic regression analysis was done to assess the association between the dependent variable with each independent variable. The socio-demographic factors, knowledge, attitude, and practice of preventive measures against COVID-19 were the factors included in the bivariate logistic regression analysis. Thus, independent variables with a p-value of less than 0.25 were considered in the final model. Correlation between independent variables was assessed but we did not find any correlation between independent variables. The model fitness was also checked using the Hosmer-Lemeshow model fit-ness test. Finally, multivariable logistic regression analysis was done to control potential confounders and to identify the factors associated with the psychological impact of COVID-19 among students. The statistical significance level was declared at a P-value $<0.05$.

\section{Operational Definitions}

Psychological problem: students who were experienced all of Depression, Anxiety, and Stress Scale (DASS-21) [29] were considered as students affected by the psychological impacts of COVID-19.

Knowledge level: students who were correctly answered $70 \%$ or more (14/20) of the knowledge questions were considered as students with a good knowledge level while students who answered correctly below $70 \%$ of the knowledge questions were considered as having poor knowledge.

Attitude level: students who were correctly answered $70 \%$ or more (5.6/8) of the attitude questions were considered as students with a positive attitude while students who correctly answered below $70 \%$ of the attitude questions were considered as students with a negative attitude. 
Practice level: students who were correctly answered $70 \%$ or more $(8.5 / 12)$ of the practice questions were considered as students with a good practice e level while students who correctly answered below $70 \%$ of the practice questions were considered as students with a poor practice.

\section{Results:}

\section{Sociodemographic characteristics of Participants}

In this study, 422 participants were involved with a response rate of $96.6 \%$. The median age of the participants was 21 years with three Interquartile Range (IQR). Of the total students; 155 (38.0\%) were lived in the rural residence, $194(47.5 \%)$ were females, $215(52.7 \%)$ were learning TVET or diploma level training, and 340 (83.3\%) were living with their families during the COVID-19 lockdown. In this study, the participants had a median of 5 total family size with 3 IQR (Table 1).

Table 1: Sociodemographic, knowledge, attitude and practices of students in Dessie town Private and Public Colleges/Universities, Amhara region, Ethiopia, $2020(n=408)$

\begin{tabular}{llll}
\hline List of Predictors & Category of variables & Frequency (\#) & Percentage (\%) \\
\hline Age of participants (in years) & $16-20$ & 166 & 40.7 \\
& More than 20 & 242 & 59.3 \\
Residence & Urban & 253 & 62.0 \\
& Rural & 155 & 38.0 \\
Sex of the participants & Male & 214 & 52.5 \\
& Female & 194 & 47.5 \\
Marital status & & & \\
& Single* & 360 & 88.2 \\
& Married & 48 & 11.8 \\
Religion of the participants & Orthodox & 207 & 50.7 \\
& Muslim & 183 & 44.9 \\
& Others+ & 18 & 4.4 \\
Type of Education enrollment & TVET (Diploma) & 215 & 52.7 \\
& Degree (First) & 193 & 47.3 \\
\hline
\end{tabular}




\begin{tabular}{|c|c|c|c|}
\hline \multirow[t]{2}{*}{ Program } & Regular & 377 & 92.4 \\
\hline & Evening (Extension) & 31 & 7.6 \\
\hline \multirow[t]{3}{*}{ Field of Study } & Health related & 233 & 57.1 \\
\hline & Business related & 129 & 31.6 \\
\hline & Technology related & 46 & 11.3 \\
\hline \multirow[t]{4}{*}{ Academic year } & Year I & 151 & 37.0 \\
\hline & Year II & 180 & 44.1 \\
\hline & Year III & 58 & 14.2 \\
\hline & Year IV+ & 19 & 4.7 \\
\hline \multirow[t]{4}{*}{ Living with; } & Families & 340 & 83.3 \\
\hline & Relatives & 28 & 6.9 \\
\hline & Alone & 21 & 5.1 \\
\hline & Others++ & 19 & 4.7 \\
\hline \multirow{2}{*}{$\begin{array}{l}\text { Total family size (including extended } \\
\text { families) }\end{array}$} & $<5$ & 198 & 48.5 \\
\hline & $5+$ & 210 & 51.5 \\
\hline \multirow{3}{*}{$\begin{array}{l}\text { Monthly income for education (in } \\
\text { ETB) }\end{array}$} & $<1000$ & 349 & 85.5 \\
\hline & $1000-1500$ & 47 & 11.5 \\
\hline & $>1500$ & 12 & 2.9 \\
\hline \multirow[t]{2}{*}{ Knowledge level } & Poor & 124 & 30.4 \\
\hline & Good & 284 & 69.6 \\
\hline \multirow[t]{2}{*}{ Attitude level } & Negative & 178 & 35.0 \\
\hline & Positive & 230 & 65.0 \\
\hline \multirow[t]{2}{*}{ Practice levels } & Poor & 143 & 43.6 \\
\hline & Good & 265 & 56.4 \\
\hline
\end{tabular}

Keynote: Single* (living together, divorced, and widowed), Others+ (Protestant, Catholic), Others++ (friends, sister/son-in-laws)

\section{COVID-19 and its Psychological Impact on Students}

In this study, the overall psychological effect of COVID-19 among college students was $16.2 \%$ (95\% CI: 12.7\%, 19.9\%) which was measured using the students' experience of all anxiety, depression, and stress disorders. Moreover, 315 (77.2\%) of the students had reported that they 
are experienced depression disorder. Similarly, 293 (71.8\%) and 198 (48.5\%) of students had experienced anxiety and stress disorders respectively (Fig. 1).

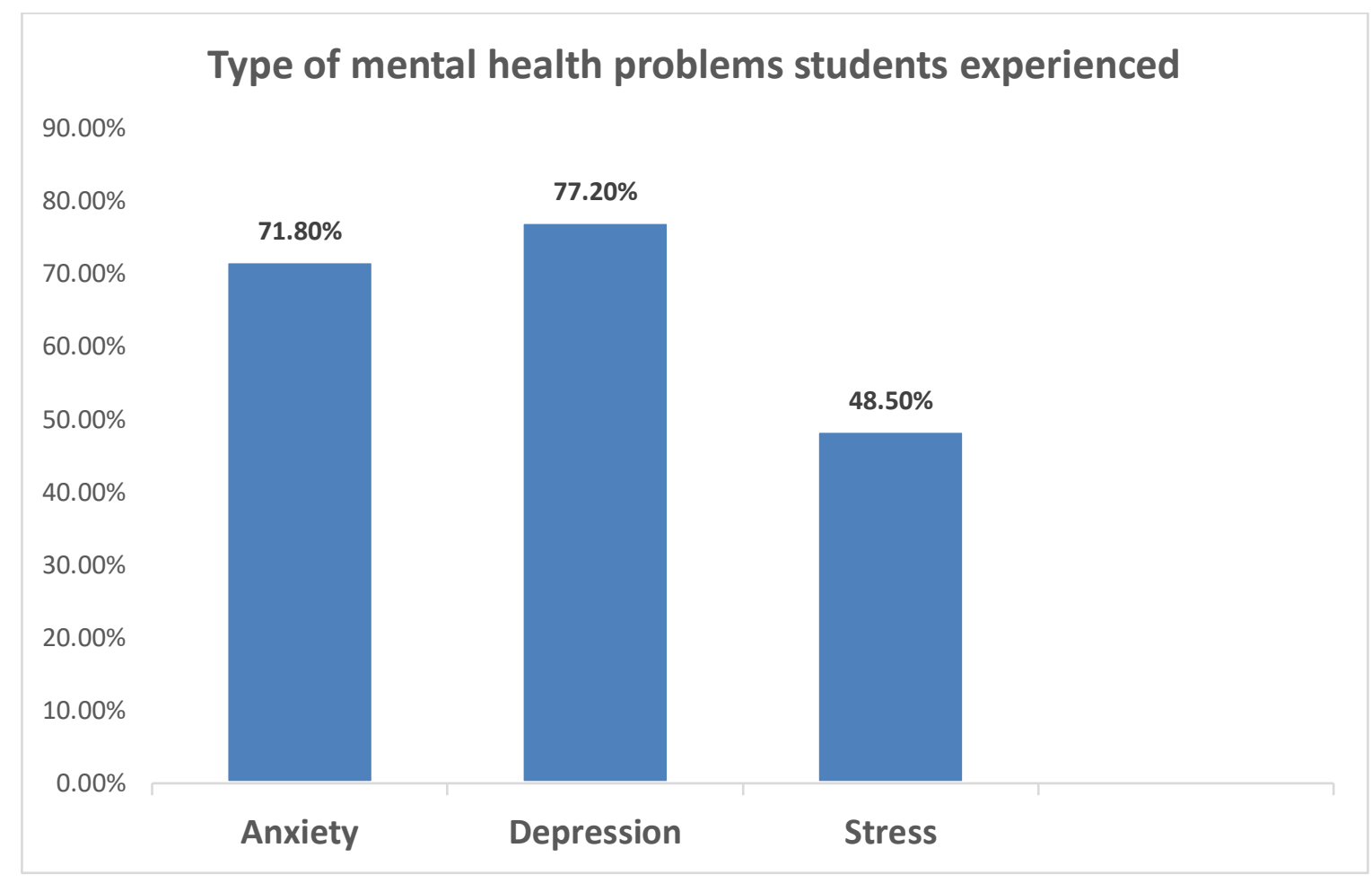

Figure 1: Types of psychological problems students experienced during the lockdown of COVID-19, June 2020, Ethiopia.

\section{Determinants of Psychological Problems among Students during COVID-19}

The selection of variables to be entered into a multivariable logistic regression model was based on clinical significance, predictor variables with $\mathrm{p}$-value $<0.25$ in the bivariable logistic regression, and absence of multi-collinearity between independent variables. In this study, the selected covariates include; the sex of participants, residence, field of study, living conditions, attitude level, and practice of preventive measures against COVID-19 were entered into the multivariable logistic regression analysis model. The multivariable logistic regression model was done with backward elimination methods.

In this study, the odds of the psychological effect of COVID among female students was twice higher compared to male students $[\mathrm{AOR}=1.68,95 \%$ CI $1.09,2.91]$. students with inadequate practice of prevention and control measures had experienced twice greater odds of the psychological impacts of COVID 19 compared to students having adequate practices 
[AOR=1.74: 95\% CI 1.01, 3.02]. Moreover, students who were living in urban residency had 24\% less likely to experience psychological problems compared to students currently living in rural areas $[\mathrm{AOR}=0.76$ : 95\% CI 0.48, 0.94]. However, sex of participants, field of study, living conditions, and attitude towards COVID 19 were not significantly associated with the psychological impacts of COVID-19 among students (Table 2).

Table 2: Factors associated with psychological impacts among students in colleges/ universities in Dessie, town, Amhara region, Ethiopia, 2020

\begin{tabular}{|c|c|c|c|c|c|}
\hline \multirow[t]{2}{*}{ List of variable } & \multirow{2}{*}{$\begin{array}{l}\text { Category of } \\
\text { variables }\end{array}$} & \multicolumn{2}{|c|}{ Psychological Impacts } & \multirow[t]{2}{*}{ COR $(95 \% \mathrm{CI})$} & \multirow[t]{2}{*}{$\operatorname{AOR}(95 \% \mathrm{CI})$} \\
\hline & & $\begin{array}{l}\text { Present } \\
(\%)\end{array}$ & $\begin{array}{l}\text { Absent } \\
(\%)\end{array}$ & & \\
\hline \multirow[t]{2}{*}{ Residence } & Urban & $38(57.6)$ & $215(62.9)$ & $0.81(0.47,1.37)$ & $0.76(0.48,0.94)^{*}$ \\
\hline & Rural & $28(42.4)$ & $127(37.1)$ & 1.00 & 1.00 \\
\hline \multirow{2}{*}{$\begin{array}{l}\text { Sex of } \\
\text { participants }\end{array}$} & Females & $41(62.1)$ & $173(50.6)$ & $1.61(0.93,2.75)$ & $1.68(1.09,2.91)^{*}$ \\
\hline & Males & $25(37.9$ & $169(49.4)$ & 1.00 & 1.00 \\
\hline \multirow[t]{3}{*}{ Field of study } & Health related & $35(53.0)$ & $198(57.9)$ & 1.00 & 1.00 \\
\hline & Business & $23(34.8)$ & $106(31.0)$ & $1.23(0.69,2.18)$ & $1.38(0.74,2.57)$ \\
\hline & Technology & $8(12.1)$ & $38(11.1)$ & $1.19(0.51,2.76)$ & $1.54(0.63,3.77)$ \\
\hline \multirow[t]{2}{*}{ Living with; } & Family & $61(92.4)$ & $279(81.6)$ & 1.00 & 1.00 \\
\hline & Others+ & $5(7.6)$ & $63(18.4)$ & $0.36(0.14,0.94)$ & $0.94(0.25,3.48)$ \\
\hline \multirow[t]{2}{*}{ Attitude } & Negative & $32(48.5)$ & $146(42.7)$ & $1.26(0.76,2.14)$ & $1.42(0.81,2.51)$ \\
\hline & Positive & $34(51.5)$ & $196(57.3$ & 1.00 & 1.00 \\
\hline \multirow[t]{2}{*}{ Practice level } & Inadequate & $31(47.0)$ & $112(32.7)$ & $1.82(1.07,3.10)$ & $1.74(1.01,3.02)^{*}$ \\
\hline & Adequate & $35(53.0)$ & $230(67.3)$ & 1.00 & 1.00 \\
\hline
\end{tabular}

Key: COR- Crude Odds Ratio, AOR- Adjusted Odds Ratio, * P-value < 0.05, Others+ (alone, relatives, and friends)

\section{Discussion}

In this study, the overall psychological effect of COVID-19 among college students was low that was measured using the experience of all of anxiety, depression, and stress disorders. The multivariable logistic regression model showed that residence, poor practice, and sex of the 
participants were the independent predictors of the psychological impact of COVID 19 among students.

In this study, the overall psychological impact of COVID-19 among college students was $16.2 \%$. This finding is lower than studies conducted in northern Ethiopia (85.3\%) [27], University of Dhaka (43.4\%) [32], Jilin Province, China (40.4\%) [33], 194 cities in China (53.8\%) [34]. The outbreak of COVID-19 has shown many psychological problems [35] that need provision of improved psychological interventions at national, regional, and district levels. The discrepancy might be due to differences in the measurement of the psychological problems. In the current study, psychological problem among students was measured using the co-existence of all of anxiety, stress and depression. However, the psychological problem in the previous study was measured using either stress or anxiety or depression.

In our study, more than three-fourth $(77.2 \%)$ of the students had experienced depression disorder. This finding is higher than studies conducted in Hubei Province, China (37.1\%) [36], and 194 cities in China (16.5\%) [34]. Furthermore, our study showed that nearly three-fourth (71.8\%) of students had experienced anxiety disorders during the lockdown. This finding is higher than a study conducted in China that found only one-fourth (25\%) of college students presented anxiety disorder [19]. This finding is also higher than studies conducted in Hubei Province, China (29\%) [36], and 194 cities in China (28.8\%) [34]. Moreover, in this study, nearly fifty percent (48.5\%) of students had experienced stress disorders during the lockdown. This finding is higher than studies conducted in Samara University, Northeast Ethiopia (53.2\%) [37] and 194 cities in China (8.1\%) [34]. In Ethiopia, the widespread outbreak of COVID 19 is directly associated with these adverse mental health consequences among students who are out of school.

In this study, the odds of psychological impact of COVID among female students was twice higher compared to male students. This finding is similar to studies conducted in Hubei Province, China [36], and Jilin Province, China [33]. In Ethiopia, female students prone to gender-based violence, poor social and economic support [37, 38]. Consequently, these conditions can easily lead them into loose of self-confidence and many stressors in life. Hence, they are victims of stress disorders compared to their counterparts, male students.

This study revealed that students who were living in urban residency had $24 \%$ less likely to experience psychological problems compared to students currently living in rural areas. This 
finding is similar to a study conducted in China [19]. Moreover, students with poor preventive practice had experienced twice greater odds of psychological impacts of COVID 19 compared to students having adequate practices. Many studies revealed that students out of school and in the final stage of graduation are more prone to many psychological crises [17, 33] which is due to poor adherence to the preventive measure of COVID 19 pandemic.

Limitation of the study: the study was done using a phone call interviews which may be prone to social desirability bias. Besides, the study was not involved adolescents in high schools and precollege schools. Thus, it may not represent all of the adolescents in Dessie town. Moreover, the study also share the limitations of a cross-sectional study design.

\section{Conclusions}

In this study, the overall psychological impact of COVID 19 among students was low. The multivariable logistic regression analysis showed residence, sex, and level of preventive practice were the independent predictors of psychological problems among students.

However, the level of anxiety, stress, and depression disorders are optimally high among students. Therefore, the Ministry of Sciences and Higher Education [MOSHE] and local governments should develop effective strategies and interventions to address students with psychological problems. Moreover, it is important to consider the educational enrollment types and academic years of the students during the interventions.

\section{List of Abbreviations}

AOR

COR

COVID 19

DASS

DSTC

WHO
Adjusted Odds Ratio

Crude Odds Ratio

Corona Virus Diseases 19

Depression, Anxiety, Stress Scale

Dream Science and Technology College

World Health Organization 


\section{Declarations}

\section{Ethical Issues and Consent to Participate}

The ethical approval was obtained from Dream Science and Technology Institutional Health Research Ethics Review Committee with approval letter of DSTC/DHS/031/2020. Then, permission letter was written for selected Colleges for cooperation and support. We had obtained verbal consent from individual study participants before beginning of data collection. We avoided personal identifier to ensure confidentiality and anonymity of study participants.

\section{Consent to publish}

Not applicable

\section{Availability of Data and Materials}

All materials and data related to this article are included in the main document of the manuscript. However, if anyone has interested to have raw data, he/she can contact the corresponding author.

\section{Competing Interests}

The authors declare that they have no competing interests.

\section{Funding source}

Not applicable.

\section{Authors' Contributions}

All authors conceived and designed the study. AWT, and GB supervised the data collection. AWT, AM and SM performed the data analysis, interpretation of data, and drafted the manuscript and critically reviewed the manuscript. All authors read and approved the final manuscript.

\section{Acknowledgements}

We would like to than Dream science and Technology College for its ethical approval. Furthermore, our deepest gratitude goes to the hospital staffs, participants, data collectors and supervisors. 


\section{List of References}

1. Skowronski DM, Astell C, Brunham RC, Low DE, Petric M, et al. Severe acute respiratory syndrome (SARS): a year in review. Annu Rev Med 2005, 56:357-381.

2. Wu D, Wu T, Liu Q, Yang Z. The SARS-CoV-2 outbreak: what we know. International Journal of Infectious Diseases 2020.

3. Zumla A, Hui DS, Perlman S. Middle East respiratory syndrome. The Lancet 2015, 386(9997):995-1007.

4. Lu H, Stratton CW, Tang YW. Outbreak of Pneumonia of Unknown Etiology in Wuhan China: the Mystery and the Miracle. Journal of Medical Virology.

5. $\quad$ CDC. People who are at higher risk for severe illness. Retrieved April 5th 2020.

6. Wang Y, Xu B, Zhao G, Cao R, He X, Fu S. Is quarantine related to immediate negative psychological consequences during the 2009 H1N1 epidemic? General hospital psychiatry 2011, 33(1):75-77.

7. Tsai YY. Public risk perceptions, communications, and trust: A comparison of the SARS and the novel influenza H1N1 outbreaks in Taiwan. China Media Research 2010, 6:69-79.

8. Cowling BJ, Ng DM, Ip DK, Liao Q, Lam WW, et al. Community psychological and behavioral responses through the first wave of the 2009 influenza A (H1N1) pandemic in Hong Kong. The Journal of infectious diseases 2010, 202(6):867-876.

9. Holmes EA, Ghaderi A, Harmer CJ, Ramchandani PG, Cuijpers P, et al. The Lancet Psychiatry Commission on psychological treatments research in tomorrow's science. The Lancet Psychiatry 2018, 5(3):237-286.

10. Burke RM. Active monitoring of persons exposed to patients with confirmed COVID-19United States, January-February 2020. MMWR Morbidity and mortality weekly report 2020, 69.

11. Zettler I, Schild C, Lilleholt L, Böhm R. Individual differences in accepting personal restrictions to fight the COVID-19 pandemic: Results from a Danish adult sample. 2020.

12. Dong Y, Mo X, Hu Y, Qi X, Jiang F, Jiang Z, Tong S: Epidemiology of COVID-19 among children in China. Pediatrics 2020.

13. Roy-Byrne PP, Davidson KW, Kessler RC, Asmundson GJ, Goodwin RD, et al. Anxiety disorders and comorbid medical illness. General hospital psychiatry 2008, 30(3):208-225.

14. Smeeding SJ, Bradshaw DH, Kumpfer K, Trevithick S, Stoddard GJ. Outcome evaluation of the Veterans Affairs Salt Lake City Integrative Health Clinic for chronic pain and stressrelated depression, anxiety, and post-traumatic stress disorder. The Journal of alternative and complementary medicine 2010, 16(8):823-835.

15. Kiecolt-Glaser JK, McGuire L, Robles TF, Glaser R. Psychoneuroimmunology: Psychological influences on immune function and health. Journal of consulting and clinical psychology 2002, 70(3):537.

16. Glaser R, Kiecolt-Glaser JK. Handbook of human stress and immunity: Academic Press; 2014.

17. Lee J. Mental health effects of school closures during COVID-19. The Lancet Child \& Adolescent Health 2020, 4(6):421.

18. Wang C, Pan R, Wan X, Tan Y, Xu L, Ho CS, Ho RC. Immediate psychological responses and associated factors during the initial stage of the 2019 coronavirus disease (COVID-19) epidemic among the general population in China. International journal of environmental research and public health 2020, 17(5):1729. 
19. Cao W, Fang Z, Hou G, Han M, Xu X, et al. The psychological impact of the COVID-19 epidemic on college students in China. Psychiatry research 2020:112934.

20. Liu N, Zhang F, Wei C, Jia Y, Shang Z, et al. Prevalence and predictors of PTSS during COVID-19 Outbreak in China Hardest-hit Areas: Gender differences matter. Psychiatry research 2020:112921.

21. Xiang Y-T, Yang Y, Li W, Zhang L, Zhang Q, et al. Timely mental health care for the 2019 novel coronavirus outbreak is urgently needed. The Lancet Psychiatry 2020, 7(3):228-229.

22. Yao H, Chen J-H, Xu Y-F. Patients with mental health disorders in the COVID-19 epidemic. The Lancet Psychiatry 2020, 7(4):e21.

23. Jemal B, Ferede ZA, Mola S, Hailu S, Abiy S, et al. Knowledge, attitude and practice of healthcare workers towards COVID-19 and its prevention in Ethiopia: a multicenter study. 2020.

24. FMOH: COVID 19 Handbook for health professionals Federal Minstry of Health, Ethiopia, Availabile: https://www. www.moh.gov.et_accessed on May 12, 2020.

25. FMOH: Infection Prevention and Control Interim Protocol for COVID-19 In Health Care Settings in Ethiopia. April, 2020. Availabile: https://www. www.moh.gov.et accessed on May 12, 2020

26. McBride O, Murphy J, Shevlin M, Gibson-Miller J, Hartman TK, Hyland P, Levita L, Mason L, Martinez AP, McKay R: Monitoring the psychological impact of the COVID-19 pandemic in the general population: an overview of the context, design and conduct of the COVID-19 Psychological Research Consortium (C19PRC) Study. 2020.

27. Tadesse DB, Gebrewahd GT, Demoz GT. Knowledge, Attitude, Practice and Psychological response toward COVID-19 among Nurses during the COVID-19 outbreak in Northern Ethiopia, 2020. 2020.

28. Tan BY, Chew NW, Lee GK, Jing M, Goh Y, et al. Psychological impact of the COVID19 pandemic on health care workers in Singapore. Annals of Internal Medicine 2020.

29. Ng F, Trauer T, Dodd S, Callaly T, Campbell S, Berk M. The validity of the 21-item version of the Depression Anxiety Stress Scales as a routine clinical outcome measure. Acta neuropsychiatrica 2007, 19(5):304-310.

30. Joshi K, Jamadar D. Knowledge, attitude and practices regarding COVID-19 among medical students-A cross sectional study.

31. Maheshwari S, Gupta PK, Sinha R, Rawat P. Knowledge, attitude, and practice towards coronavirus disease 2019 (COVID-19) among medical students: A cross-sectional study. Journal of Acute Disease 2020, 9(3):100.

32. Imtiaz A, Hasan ME, Hossain MA, Khan NM. Attitudes toward COVID-19 among Young Adults: Role of Psychological Distress. 2020.

33. Liang L, Ren H, Cao R, Hu Y, Qin Z, Li C, Mei S. The Effect of COVID-19 on Youth Mental Health. Psychiatric Quarterly 2020.

34. Qiu J, Shen B, Zhao M, Wang Z, Xie B, Xu Y. A nationwide survey of psychological distress among Chinese people in the COVID-19 epidemic: implications and policy recommendations. General psychiatry 2020, 33(2).

35. Duan L, Zhu G. Psychological interventions for people affected by the COVID-19 epidemic. The Lancet Psychiatry 2020, 7(4):300-302.

36. Ahmed MZ, Ahmed O, Aibao Z, Hanbin S, Siyu L, Ahmad A. Epidemic of COVID-19 in China and associated Psychological Problems. Asian journal of psychiatry 2020:102092. 
37. Tesfaye Kelemu R, Bayray Kahsay A, Ahmed KY. Prevalence of Mental Distress and Associated Factors among Samara University Students, Northeast Ethiopia. Depression Research and Treatment 2020, 2020:7836296.

38. Solomon A, Mihretie G, Tesfaw G. The prevalence and correlates of common mental disorders among prisoners in Addis Ababa: an institution based cross-sectional study. BMC Research Notes 2019, 12(1):394. 
Figures

\section{Type of mental health problems students experienced}

$90.00 \%$

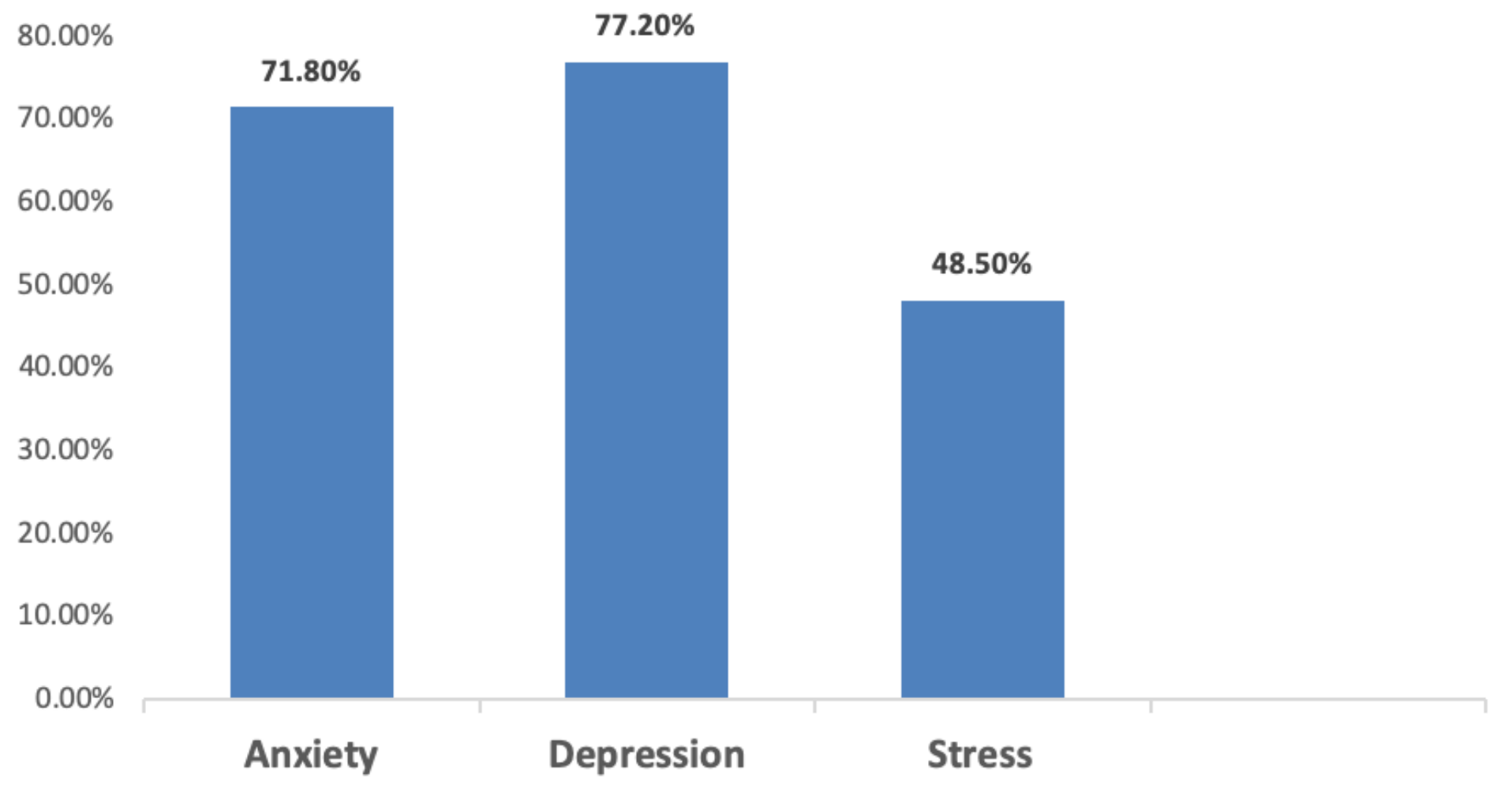

\section{Figure 1}

Types of psychological problems students experienced during the lockdown of COVID-19, June 2020, Ethiopia. 